\title{
BMJ Open Use of multiple antidiabetic medications in patients with diabetes and its association with hypoglycaemic events: a case-crossover study in Jordan
}

\author{
Abdallah Y Naser, ${ }^{1}$ lan Chi Kei Wong, ${ }^{1,2}$ Cate Whittlesea, ${ }^{1}$ Maedeh Y Beykloo, ${ }^{1}$ \\ Kenneth K C Man, ${ }^{1,2,3}$ Wallis C Y Lau, ${ }^{1}$ Dana Abdel-Halim Hyassat, ${ }^{4}$ Li Wei ${ }^{1}$
}

To cite: Naser AY, Wong ICK, Whittlesea C, et al. Use of multiple antidiabetic medications in patients with diabetes and its association with hypoglycaemic events: a case-crossover study in Jordan. BMJ Open 2018;8:e24909. doi:10.1136/ bmjopen-2018-024909

- Prepublication history for this paper is available online. To view these files, please visit the journal online (http://dx.doi org/10.1136/bmjopen-2018024909).

Received 20 June 2018 Revised 2 October 2018 Accepted 9 0ctober 2018

Check for updates

(c) Author(s) (or their employer(s)) 2018. Re-use permitted under CC BY-NC. No commercial re-use. See rights and permissions. Published by BMJ.

${ }^{1}$ Research Department of Practice and Policy, UCL School of Pharmacy, London, UK ${ }^{2}$ Centre for Safe Medication Practice and Research, Department of Pharmacology and Pharmacy, The University of Hong Kong, Hong Kong, China ${ }^{3}$ Department of Medical Informatics, Erasmus University Medical Centre, Rotterdam, The Netherlands

${ }^{4}$ National Centre for Diabetes, Endocrinology and Genetics, Amman, Jordan

Correspondence to Dr LiWei; I.wei@ucl.ac.uk

\section{ABSTRACT}

Objective To assess whether the use of multiple antidiabetic medications is associated with an increased risk of hypoglycaemia in patients with type 2 diabetes mellitus.

Design A case-crossover study.

Setting Cases were enrolled from the National Center for Diabetes, Endocrinology and Genetics in Amman, Jordan. Participants Patients were those with diabetes mellitus and reported incident of a hypoglycaemic event in their medical records during the period January 2007 to July 2017. Patients with multiple antidiabetic medications were those with at least two antidiabetic medications.

Primary outcome History of antidiabetic medication use was extracted from the pharmacy records. The use of multiple antidiabetic medications during the risk window (before hypoglycaemia) was compared with a control window(s) (earlier time) of the same length after a washout period. Conditional logistic regression was applied to evaluate the $\mathrm{OR}$ of hypoglycaemia between the treatment groups. A secondary analysis was performed in patients with a blood glucose measurement of $\leq 70 \mathrm{mg} / \mathrm{dL}$.

Results 182 patients (106 females, 58.2\%) were included in the study with an average age of 59.9 years ( $S D=9.9)$. The patients' average body mass index was $31.7 \mathrm{~kg} / \mathrm{m}^{2}$ (SD=6.2). Compared with monotherapy, the OR of hypoglycaemic events for patients with multiple antidiabetic medications was 5.00 (95\% Cl 1.10 to 22.82). The OR was 6.00 ( $95 \% \mathrm{Cl} 0.72$ to 49.84 ) for the secondary analysis patient group $(n=94)$. Ten-fold increased risk was found in patients $(n=155)$ with insulin and sulfonylureabased combination therapy (OR 10.00;95\% $\mathrm{Cl} 1.28$ to 78.12).

Conclusion This study shows that the use of multiple antidiabetic medications appears to increase the risk of hypoglycaemic events. Patients and healthcare professionals should be extra vigilant when patients are on multiple antidiabetic medications therapy, especially the combination of sulfonylurea and insulin.

\section{INTRODUCTION}

Diabetes mellitus (DM) is a progressive disease and patients need to be treated efficiently to prevent the development of its

\section{Strengths and limitations of this study}

- This study provides evidence for a better understanding of the association between the use of multiple antidiabetic medications and hypoglycaemia.

- This is the first study to investigate this association in the Middle East and to extend the generalisability of the current evidence beyond the Caucasian population.

- The use of case-crossover as a self-matching study design minimised the effect of time-independent confounders.

- The small sample size of our study cohort led to wide Cls and some results did not reach a statistically significant level.

complications. ${ }^{1}$ Comprehensive management for patients with uncontrolled diabetes includes an appropriate dietary plan, exercise and antidiabetic medication therapy. However, antidiabetic monotherapy does not always achieve the optimal blood glucose control, ${ }^{2}$ and patients may need intensive antidiabetic therapy in order to reduce the blood glucose level to a normal range. ${ }^{3}$ Treatment intensification can be done either through increasing the dose of a single antidiabetic agent, or by administration of combination therapy using multiple antidiabetic medications. ${ }^{4}$

Previous studies across different countries have shown that the prevalence rate of hypoglycaemic events has increased during the past decade,$^{5-7}$ highlighting that there is a continuous problem among patients with DM and their current antidiabetic treatment. A recent ecological study observed increases in both the prescribing of multiple antidiabetic medications and the rate of hospitalised hypoglycaemic events in the UK. ${ }^{7}$ However, the results do not necessarily infer that use of multiple antidiabetic medications therapy 
was associated with the increase in hypoglycaemic events. Previous studies have only assessed the effectiveness and safety of individual drug or combination therapies in relation to hypoglycaemic outcomes. Therefore, there is a lack of evidence on the effect of the number of antidiabetic drug used on the risk of hypoglycaemic events. This study aimed to determine whether the risk of hypoglycaemic events is increased by exposure to multiple antidiabetic medications.

\section{METHODS}

\section{Data source and extraction}

This study was conducted using patients' medical records from the National Center for Diabetes, Endocrinology and Genetics (NCDEG) registry. ${ }^{8}$ The NCDEG is an independent non-profit healthcare organisation in Amman, Jordan. It was established in 1996 to provide healthcare of high quality, education and training in the fields of diabetes, endocrinology and genetic diseases to more than 25000 patients. This centre provides healthcare services to patients under governmental and private health insurance and for private patients who are willing to self-fund their healthcare. It is designated as a WHO collaborating centre for diabetes research, education and primary health care. ${ }^{8}$ Healthcare services are provided to patients with diabetes through a multidisciplinary team of specialised endocrinologists, specialised nurses, diabetic educators, clinical nutritionists and podiatrists. ${ }^{8}$ The scientific and technical standards of data processing and healthcare services provision in the centre meet WHO standards. ${ }^{9}$ Hypoglycaemic events were identified through a manual search of patients' medical records, and antidiabetic medications dispensing data were extracted from the pharmacy records. Patients reported the hypoglycaemic events data, and they were confirmed and documented in the medical records by the treating physician.

\section{Study design}

A case-crossover study ${ }^{10}$ was conducted to evaluate the association between the use of multiple antidiabetic medications therapy and the risk of hypoglycaemia among patients with DM. The case-crossover design is a variant of case-control study design. ${ }^{11}$ It has the advantage of minimising the effect of measured and unmeasured confounding variables, and does not require a large number of patients because the cases themselves act as the control in this type of study design. ${ }^{11} 12$ Only individuals with hypoglycaemic events were included in the study. Therefore, time-invariant confounding factors such as patients' characteristics (sex and family history), smoking status, type of diabetes, presence of comorbid diseases or any unmeasured confounders constant over time were eliminated. The case-crossover design minimise bias that may be caused by selective selection of controls, which is a common problem in case-control studies. ${ }^{10}$ The case-crossover design has been used previously to study adverse drug reactions. ${ }^{13-15}$ The case-crossover design compares the exposure of interest which is exposure odds of multiple antidiabetic medications therapy during a defined case window (or risk window) with the odds in the preceding control window(s) within the same patients as shown in figure 1 .

\section{Study outcome and case definition}

The outcome was defined as all hypoglycaemic events between January 2007 and July 2017. Cases were identified as all patients who met the following inclusion criteria:

1. With type 2 DM.

2. A hypoglycaemic event during the study period.

3. At least 12 months medical records history before the date of hypoglycaemia event (index date).

\section{Risk and control window definition}

The case window (or the risk window) is the period before the recorded hypoglycaemic event (index date). The control window is the period that precedes this case window. Between the case window and the control window, a washout period was included to minimise the possibility of any carryover effect from the control period to the risk period. ${ }^{16}$ A 15-day window was selected for the primary analysis. The risk window of 30 days was used for the sensitivity analysis to test the robustness of the findings of the primary analysis. For the primary analysis, the exposure to multiple antidiabetic medications therapy in the 15 days (days $1-15$ before the index date) that preceded the event (the risk window) was compared with a preceding control period of the same length (days 46-60 before the index date), with a washout period of 30 days (days 16-45 before the index date) between the risk window and the control window, refer to figure 1 .

\section{Exposure definition}

The use of multiple antidiabetic medications therapy was defined as the concurrent use of two or more antidiabetic

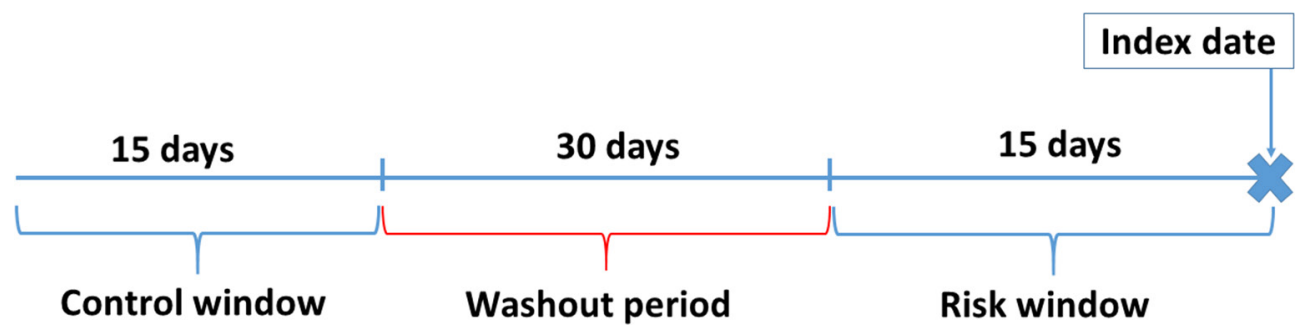

Figure 1 Risk and control windows in the study design. 
medications. The full medications use history was retrieved from the pharmacy records for each patient.

\section{Data quality control}

The data were extracted manually from the medical records of the patients by the researcher (AYN) using a predesigned data extraction form. The accuracy and the quality of the data entry and extraction were checked by another pharmacist from random sample of 20 records. The accuracy of the extracted data was $100 \%$.

\section{Patient and public involvement}

Patients were not involved in any aspect of the design or conduct of this study.

\section{Statistical analysis}

Descriptive statistics were used to describe patients' demographic characteristics, medications use and comorbidities. Continuous data were reported as mean $\pm \mathrm{SD}$, and categorical data were reported as percentages (frequencies). Conditional logistic regression was used to estimate the OR for comparing the use of multiple antidiabetic medications therapy during the risk window with the control window, compared with that for antidiabetic monotherapy. A two-sided $\mathrm{p}<0.05$ was considered as statistically significant.

\section{Secondary and sensitivity analyses}

Secondary analysis was performed to calculate the OR for patients with confirmed hypoglycaemic events and blood glucose measurement $(\leq 70 \mathrm{mg} / \mathrm{dL})$ as recommended by the American Diabetes Association. ${ }^{17}$ Sensitivity analyses were conducted: using 30 days risk window (model number 1), using 7 days washout period (model number 2) and using multiple (four) control windows (model number 3 ). In addition, the same analyses were performed for patients taking multiple antidiabetic therapies based on insulin or sulfonylurea. These sensitivity analyses used different inclusion criteria for study cases, with confirmed hypoglycaemia with blood glucose measurement $(\leq 70 \mathrm{mg} / \mathrm{dL})$, shorter washout period to assess the internal validity of the drug use, ${ }^{18}$ and multiple control windows to increase the statistical power of estimates as recommended in the literature, ${ }^{19}$ thereby increased the reliability of the OR calculations. All the analyses were conducted using Stata (V.15).

\section{RESULTS}

\section{Cohort size and patient characteristics}

Of 470 patient records were reviewed, 183 patients with an incident of hypoglycaemia and met the inclusion criteria were identified. One patient was diagnosed with prediabetes, and thus was excluded from the study. For secondary analysis, cases were restricted to patients who had blood glucose measurements of $\leq 70 \mathrm{mg} / \mathrm{dL} \quad(\mathrm{n}=94$ patients), as shown in figure 2.

\section{Patient characteristics}

Of the 182 patients, $58.2 \%(\mathrm{n}=106)$ were females. The average age was 59.9 years old $(\mathrm{SD}=9.9)$. The average body mass index (BMI) of the patients was $31.7 \mathrm{~kg} / \mathrm{m}^{2}$ $(\mathrm{SD}=6.2)$. The majority of patients were married $(\mathrm{n}=158$, $86.8 \%)$ and $30(16.5 \%)$ reported a family history of DM. While $26.4 \% \quad(n=48)$ of patients were either smokers or ex-smokers, none of the patients reported any current or previous alcohol consumption. Demographics characteristics of patients in the primary study cohort and the secondary subcohort was comparable and is shown in table 1.

The majority of the patients $(n=167,91.8 \%)$ were diagnosed with, and receiving treatment for more than one chronic condition. The two most common chronic conditions in the study sample were hypertension and dyslipidaemia, which affected around $86.3 \%$ and $76.9 \%$ of the patients, respectively. In addition to this, microalbuminuria was also prevalent $(42.3 \%)$ among the patients (table 2).

\section{Treatment characteristics}

The majority of patients were receiving oral antidiabetic medications only (as monotherapy or combination therapy) at the time when the hypoglycaemia was experienced $(n=90,49.5 \%)$. Other patients were using oral antidiabetic medications and insulin injection combination as antidiabetic therapy $(\mathrm{n}=82,45.1 \%)$, at the time of this event, followed by insulin injection use only $(n=8$, $4.4 \%$ ), and other injectable antidiabetic medications and insulin combination $(\mathrm{n}=1,0.5 \%)$. In addition, one patient $(0.5 \%)$ was managed on diet and exercise only.

The most commonly used antidiabetic therapy was combination therapy of metformin and sulfonylurea, used by $60(33.0 \%)$ patients followed by metformin and insulin combination therapy $(\mathrm{n}=55,30.2 \%)$. Patients managed using combination therapies based on sulfonylurea or insulin medications $(n=155,85.2 \%)$ were the most prevalent compared with other combination therapies. Antidiabetic dual therapy was used by 120 (65.9\%) patients with 38 patients $(20.9 \%)$ prescribed antidiabetic triple therapy and one patient $(0.5 \%)$ using of quadruple therapy. Only $12.1 \%$ of the patients $(n=22)$ were using antidiabetic monotherapy.

The use of cardiovascular system medications was noticeable and prevalent across the patients with aspirin $(\mathrm{n}=128,70.3 \%)$ and statins $(\mathrm{n}=131,72.0 \%)$ the most commonly chronic medications prescribed.

\section{Risk of hypoglycaemic event}

Table 3 shows the results of the primary, secondary and sensitivity analyses for the risk of hypoglycaemia due to the use of multiple antidiabetic medications therapy.

\section{Risk of hypoglycaemia for the primary study cohort}

Regardless of the length of risk windows ( 15 days and 30 days), the use of single or multiple control windows, and the length of washout periods ( 7 days and 30 days), 


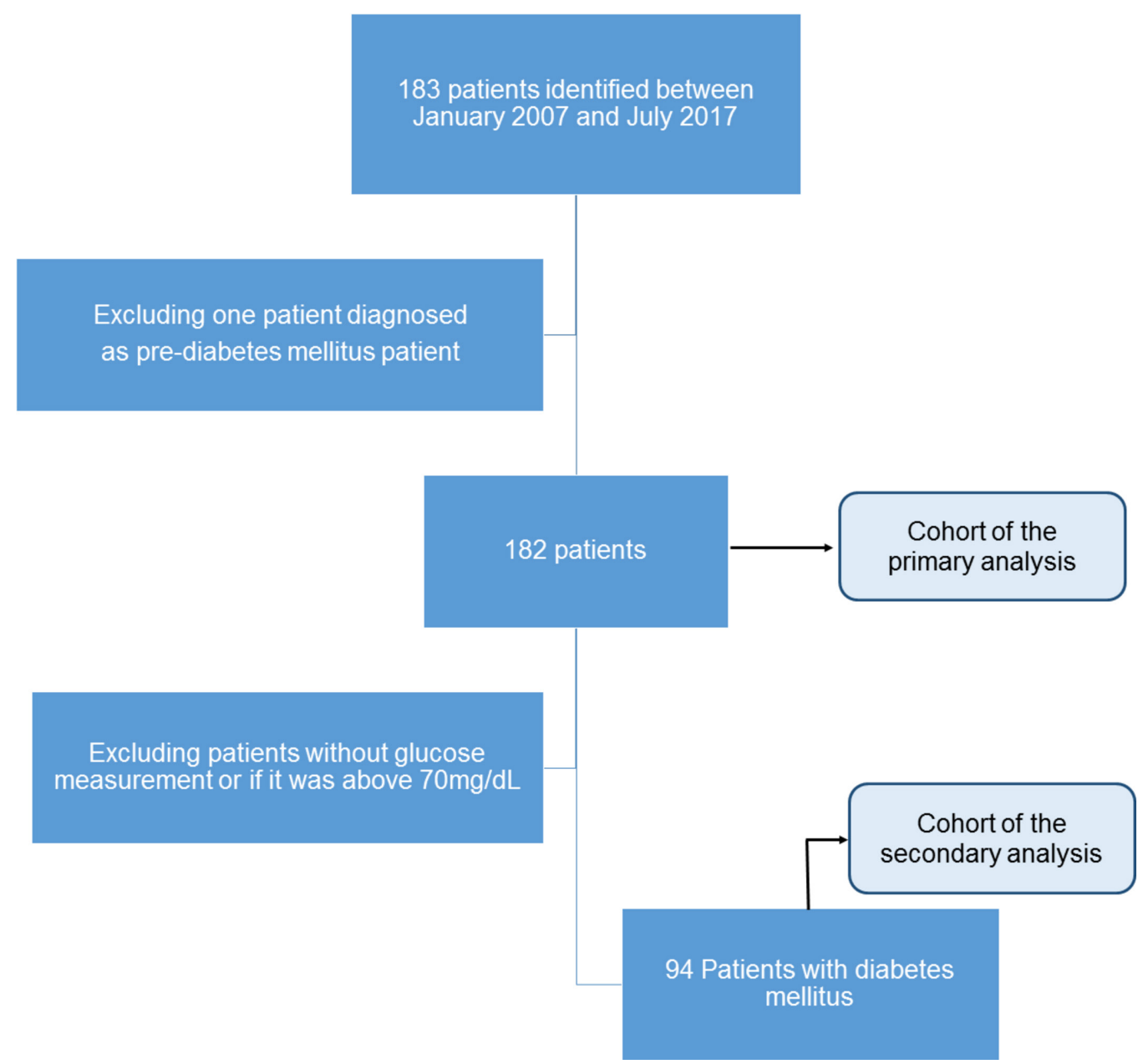

Figure 2 Flow chart of the patients included in the case-crossover study.

all primary and sensitivity analyses confirmed an increase in the risk of hypoglycaemia among users of multiple antidiabetic medications (table 3). However, some of these were not statistically significant. Compared with antidiabetic monotherapy, the OR of hypoglycaemic events for patients with DM exposed to multiple antidiabetic medications therapy was 5.00 (95\% CI 1.10 to 22.82) for the primary analysis (table 3 ). Sensitivity analyses using 30 days risk window, 7 days washout period and multiple control windows confirmed the primary analysis findings. However, some of these were statistically non-significant. In addition, another sensitivity analysis was conducted using a different definition for exposure (use of three or more antidiabetic medications), which showed the same risk direction with non-significant results due to small sample size $(n=38)$ (results are not included in this manuscript).

Risk of hypoglycaemia for patients with glucose measurement below $70 \mathrm{mg} / \mathrm{dL}$

Similar to the primary analysis, an increase in the risk of hypoglycaemia among the users of multiple antidiabetic medications therapy was observed using different risk windows, different washout period and multiple control windows, but the effects did not reach statistical significance in some of these, (see table 3). Compared with antidiabetic monotherapy, the OR of hypoglycaemic events for patients exposed to multiple antidiabetic medications therapy was 6.00 (95\% CI 0.72 to 49.84). Restriction of the study sample in the secondary subcohort analyses, to patients who had a blood glucose measurement of $\leq 70 \mathrm{mg} / \mathrm{dL}$, resulted in statistically non-significant results due to the small sample size ( $\mathrm{n}=94$ patients).

Risk of hypoglycaemia for patients on insulin or sulfonylureabased combination therapies

Insulin and sulfonylurea-based combination therapies were the most common therapies in the study cohort $(\mathrm{n}=155,85.2 \%)$. Compared with antidiabetic monotherapy, the OR of hypoglycaemic events for patients with DM who were exposed to multiple antidiabetic medications therapy based on sulfonylurea or insulin was 10.00 (95\% CI 1.28 to 78.12), which is a larger change in odds compared with the odds of being exposed to any antidiabetic combination therapy. Table 4 shows the results of the case-crossover analyses for the risk of hypoglycaemia due to the use of multiple antidiabetic medications therapy based on sulfonylurea or insulin. 
Table 1 Baseline characteristics of patients reported hypoglycaemia $(n=182)$, and for the subcohort $(n=94)$ used in the secondary analysis

\begin{tabular}{|c|c|c|}
\hline Demographics & $\begin{array}{l}\text { All subjects } \\
\text { with reported } \\
\text { hypoglycaemia } \\
n=182\end{array}$ & $\begin{array}{l}\text { Subjects } \\
\text { with glucose } \\
\text { measurement } \\
\text { below } 70 \mathrm{mg} / \\
\text { dL } n=94\end{array}$ \\
\hline Age (years $\pm S D)$ & $59.9 \pm 9.9$ & $59.2 \pm 10.1$ \\
\hline \multicolumn{3}{|l|}{ Gender } \\
\hline Male & $76(41.8)$ & 37 (39.4) \\
\hline Female & $106(58.2)$ & $57(60.6)$ \\
\hline \multicolumn{3}{|l|}{ Marital status } \\
\hline Married & $158(86.6)$ & $80(85.1)$ \\
\hline Divorced & $20(11.0)$ & $11(11.7)$ \\
\hline Single & $4(2.2)$ & $3(3.2)$ \\
\hline \multicolumn{3}{|l|}{ Smoking status } \\
\hline Non-smoker & $134(73.6)$ & $70(74.5)$ \\
\hline Ex-smoker & $18(9.9)$ & $7(7.4)$ \\
\hline Smoker & $30(16.5)$ & $17(18.1)$ \\
\hline \multicolumn{3}{|l|}{$\mathrm{BMI}$} \\
\hline Mean $\mathrm{BMI}_{ \pm} \mathrm{SD}$ & $31.7 \pm 6.2$ & $31.4 \pm 5.8$ \\
\hline $\begin{array}{l}\text { Duration of diabetes } \\
\text { mellitus (years } \pm S D \text { ) }\end{array}$ & $11.3 \pm 7.2 \dagger$ & $11.5 \pm 7.2$ \\
\hline $\begin{array}{l}\text { Family history of } \\
\text { diabetes }\end{array}$ & $30(16.5)$ & $17(18.1)$ \\
\hline \multicolumn{3}{|l|}{ Employment status } \\
\hline Employed & 49 (27.2)‡ & $24(25.5)$ \\
\hline Unemployed or retired & $131(72.8)$ & $70(74.5)$ \\
\hline $\begin{array}{l}\text { Monthly income } \\
(\mathrm{JOD})^{\star}, \text { median }(\mathrm{IQR})\end{array}$ & $400(220)$ & $380(220)$ \\
\hline Insured patients & $178(97.8)$ & 93 (98.9) \\
\hline Patients on proper diet & $106(58.2)$ & $65(69.1)$ \\
\hline $\begin{array}{l}\text { Patients performing } \\
30 \text { min exercise daily }\end{array}$ & $9(5.4) \S$ & $6(6.9)^{\star \star}$ \\
\hline $\begin{array}{l}\text { Patients compliant with } \\
\text { therapy }\end{array}$ & $174(95.6)$ & $89(94.7)$ \\
\hline $\begin{array}{l}\text { Glucose level at the time } \\
\text { of the event (mg/dL) }\end{array}$ & $60.5 \pm 14.79$ & $55.6 \pm 14.7$ \\
\hline
\end{tabular}

Data are numbers (\%) of subjects unless otherwise stated.

${ }^{*} \mathrm{n}=180$ patients.

$\dagger \mathrm{t}=180$ patients.

$\ddagger \mathrm{n}=180$ patients.

$\S n=166$ patients.

In $\mathrm{n}=114$ patients.

${ }^{* *} \mathrm{n}=87$ patients.

BMI, body mass index; JOD, Jordanian dinar.

\section{DISCUSSION}

This study found that the use of multiple antidiabetic medications therapy was significantly associated with an increased odds of hypoglycaemia, when compared with antidiabetic monotherapy. In addition, the use of antidiabetic combination therapies based on insulin or
Table 2 Prevalence of chronic diseases in the study sample

\begin{tabular}{lc}
\hline Chronic disease & No (\%), $\mathbf{n = 1 8 2}$ \\
\hline Cardiovascular diseases & $36(19.8)$ \\
Stroke & $4(2.2)$ \\
Retinopathy & $3(1.6)$ \\
\hline Foot problems (ulcer) & $5(2.7)$ \\
Nephropathy & $10(5.5)$ \\
\hline Neuropathy & $17(9.3)$ \\
\hline Hypertension & $157(86.3)$ \\
Dyslipidaemia & $140(76.9)$ \\
Gastroesophageal reflux & $4(2.2)$ \\
disease (GERD)/acid reflux & \\
Arthritis & $39(21.4)$ \\
\hline Thyroid problems & $17(9.3)$ \\
\hline Sleep apnoea & $1(0.5)$ \\
\hline Liver disease & $6(3.3)$ \\
Asthma & $3(1.6)$ \\
Cancer & $1(0.5)$ \\
\hline Depression/anxiety & $2(1.1)$ \\
Epilepsy & $1(0.5)$ \\
\hline Erectile dysfunction (out of 76 males) & $47(61.8)$ \\
\hline Microalbuminuria & $77(42.3)$ \\
\hline Migraine & $1(0.5)$ \\
\hline & \\
\hline
\end{tabular}

sulfonylurea showed a higher odds of hypoglycaemic events when compared with the use of any other antidiabetic combination therapy.

This study explored the effect of the use of multiple antidiabetic medications in general (any antidiabetic combination therapy) without restricting comparison to a specific antidiabetic agent or therapeutic classification. The use of multiple antidiabetic medications therapy was found to be associated with a fivefold increased odd of hypoglycaemia. These results were confirmed using two case definitions, the first included all patients with reported hypoglycaemic events, and the second was restricted to patients who had blood glucose measurements of $\leq 70 \mathrm{mg} / \mathrm{dL}$.

The use of multiple antidiabetic medications and hypoglycaemic events

The findings of this study support a recent ecological study conducted in the UK, ${ }^{7}$ which showed similar increasing trends between the use of multiple antidiabetic medications therapy and the risk of hypoglycaemia. Similar to our study findings, a previous database study by Hippisley-Cox and Coupland in the UK reported that the use of different antidiabetic combination therapies compared with metformin monotherapy was associated with a higher risk of hospitalisation for hypoglycaemia. ${ }^{20}$ However, the findings of their study were restricted to patients who have been hospitalised for hypoglycaemia, therefore only 
Table 3 Case-crossover results for the risk of hypoglycaemia due to the use of multiple antidiabetic medications therapy in the primary, secondary and sensitivity analyses $(n=182)$

\begin{tabular}{llllll}
\hline Analysis cohort & Analysis & $\begin{array}{l}\text { Case window } \\
\text { (days) }\end{array}$ & $\begin{array}{l}\text { Washout period } \\
\text { (days) }\end{array}$ & $\begin{array}{l}\text { Control window } \\
\text { (days) }\end{array}$ & OR (95\% Cl) \\
\hline $\begin{array}{l}\text { Patients with hypoglycaemic } \\
\text { events with any degree of }\end{array}$ & Primary & $1-15$ & $16-45$ & $46-60$ & $5.00(1.10$ to 22.82) \\
severity & Model 1 & $1-30$ & $31-60$ & $61-90$ & $9.00(1.14$ to 71.04$)$ \\
& Model2 & $1-15$ & $16-22$ & $23-37$ & $5.00(0.58$ to 42.80) \\
& Model 3 & $1-15$ & $16-22$ & $23-37,38-52$, & $11.31(2.39$ to 53.57) \\
& & & & $53-67,68-82$ & \\
Patients with glucose & Secondary & $1-15$ & $16-45$ & $46-60$ & $6.00(0.72$ to 49.84) \\
measurement $\leq 70 \mathrm{mg} / \mathrm{dL}$ & Model 1 & $1-30$ & $31-60$ & $61-90$ & $5.00(0.58$ to 42.80) \\
& Model 2 & $1-15$ & $16-22$ & $23-37$ & - \\
& Model 3 & $1-15$ & $16-22$ & $23-37,38-52$, & $17.40(2.11$ to 143.48) \\
\hline
\end{tabular}

included severe hypoglycaemic events. In Hippisley-Cox's study, ${ }^{20}$ the OR of hypoglycaemic event comparing the use of metformin monotherapy to different antidiabetic combination therapies ranged from 1.23 (95\% CI 0.84 to 1.80 ) to 23.91 ( $95 \%$ CI 19.89 to 28.75 ) for the users of sulfonylurea and insulin combination therapy. When compared with the use of three or more antidiabetic medications it ranged from 4.31 (95\% CI 3.26 to 5.68) to 13.17 (95\% CI 1.14 to 15.57 ), which were similar to our findings of an increased odds of hypoglycaemia among users of multiple antidiabetic medications.

We found that the OR for hypoglycaemia was higher among users of two or more antidiabetic medications compared with that among users of three or more antidiabetic medications, which confirmed the results of a previous study. ${ }^{20}$ Nevertheless, this could not be fully confirmed since the majority of sensitivity analyses that used the other definition for exposure (the use of three or more antidiabetic medications), did not reach significance level (results are not included in this manuscript). However, possible justification for these expected results could be that the use of more antidiabetic medications (three or more agents) is accompanied with a lower dose of each component of the antidiabetic therapy, which consequently will decrease the probability of experiencing adverse events related to high dose of multiple therapy. However, this could not be confirmed without obtaining full data about the dose of antidiabetic therapy being used and also having an appropriate sample size.

\section{The role of comorbidities and polypharmacy}

The coexistence of other chronic diseases and the wide use of other chronic medications (polypharmacy) among our study cohort could be another independent risk factor that increased the risk of hypoglycaemia. The concurrent use of such chronic medications could be a time-varying confounder as they were not included in the analysis. The average BMI of our study cohort was $31.7 \mathrm{~kg} /$ $\mathrm{m}^{2}(\mathrm{SD}=6.2)$, which is classified as obese by WHO. ${ }^{21}$ This could be another risk factor in increasing the probability of patients' experiencing hypoglycaemia. ${ }^{22}$ However, we expect that our estimate will not be affected by these baseline variables because of the short observation windows in our study design.

In our study, a cohort of patients with DM, hypertension, dyslipidaemia and microalbuminuria were the most

Table 4 Case-crossover results for the risk of hypoglycaemia due to the use of multiple antidiabetic medications therapy based on sulfonylurea or insulin $(n=155)$

\begin{tabular}{|c|c|c|c|c|c|}
\hline Analysis cohort & Analysis & $\begin{array}{l}\text { Case window } \\
\text { (days) }\end{array}$ & $\begin{array}{l}\text { Washout period } \\
\text { (days) }\end{array}$ & $\begin{array}{l}\text { Control window } \\
\text { (days) }\end{array}$ & OR (95\% Cl) \\
\hline \multirow{3}{*}{$\begin{array}{l}\text { Patients with } \\
\text { hypoglycaemic events } \\
\text { with any degree of } \\
\text { severity }\end{array}$} & Primary & $1-15$ & $16-45$ & $46-60$ & $10.00(1.28$ to 78.12$)$ \\
\hline & Model 2 & $1-15$ & $16-22$ & 23-37 & 5.00 (0.58 to 42.80$)$ \\
\hline & Model 3 & $1-15$ & $16-22$ & $\begin{array}{l}23-37,38-52 \\
53-67,68-82\end{array}$ & 13.04 (2.79 to 60.96$)$ \\
\hline \multirow{3}{*}{$\begin{array}{l}\text { Patients with glucose } \\
\text { measurement } \leq 70 \mathrm{mg} / \mathrm{dL}\end{array}$} & Model 1 & $1-30$ & $31-60$ & $61-90$ & 5.00 (0.58 to 42.80$)$ \\
\hline & Model 2 & $1-15$ & $16-22$ & $23-37$ & - \\
\hline & Model 3 & $1-15$ & $16-22$ & $\begin{array}{l}23-37,38-52 \\
53-67,68-82\end{array}$ & 17.40 (2.11 to 143.48$)$ \\
\hline
\end{tabular}


commonly coexisted diseases having a prevalence rate of $86.3 \%, 76.9 \%$ and $42.3 \%$, respectively. Previous studies have established that comorbidities such as cardiovascular diseases and chronic kidney diseases increase the risk of hypoglycaemic events. ${ }^{23}$ Likewise, the use of cardiovascular system medications (eg, aspirin, angiotensin receptor blocker, calcium channel clocker, beta-blocker and ACE inhibitors) was common across the study cohort and could have contributed to increasing the hypoglycaemic risk. $^{2425}$

\section{Strengths and weaknesses}

This study has several strengths. To our knowledge, this was the first pharmacoepidemiological study to investigate the association between the use of multiple antidiabetic medications therapy and the odds of hypoglycaemia. It is the first study in the Middle East on this topic, thus increasing the generalisability of current evidence beyond the Caucasian population. Unlike the classical cohort and case-control studies (between-subject comparison), the case-crossover study design itself (within-subject comparison) offers the advantage of eliminating the effects of time-independent confounding variables such as patients' demographics, genetic factors and family medical history that may not be commonly available. In addition, our study included hypoglycaemic events from different degrees of severity and was not restricted to severe cases that required hospitalisation, which increase the generalisability of our findings. Unlike previous studies based on prescribing data, ${ }^{20}$ we used dispensing data, which eliminated the primary non-compliance (ie, not obtaining the prescription), however, it does not guarantee full compliance. Finally, our study did not restrict the comparison to a specific antidiabetic combination therapy and studied the exposure to any antidiabetic combination therapy.

Our study also has some limitations. The relatively small sample size of our study cohort has led to wide CIs. However, we used multiple control windows in the sensitivity analyses to increase the statistical power. Patients could still have residual confounders that changed over a short period of time, such as the severity of the disease and exposure to specific high-risk medications, which could itself contribute to an increase in the odds of hypoglycaemia. However, our observation period was less than 1 year and thus the effect of such a time trend is anticipated to be low. We were not able to test the effect of the different doses of antidiabetic combination therapies used by the patients, which could have had a possible effect on hypoglycaemia. Finally, the vast majority of the patients in the study are covered by health insurance, so the results could be more representative to this population of health-insured patients, which is reported in the literature to have a significant role on increasing patient's access and use of healthcare resources and decrease their out-of-pocket spending. ${ }^{26}$

Although our study uses a different design and a completely different population, our results are very similar to previous published results, ${ }^{20}$ this serves as an external validation of our result that the use of multiple antidiabetic medications therapy increases the odds of hypoglycaemic events.

In conclusion, this study found that the use of multiple antidiabetic medications therapy was associated with an increased odd of hypoglycaemic events. Patients and healthcare professionals should be extra vigilant when patients are on multiple antidiabetic medications therapy, especially the combination of sulfonylurea and insulin.

Acknowledgements The authors acknowledge the contribution of Mohammed El-Khateeb for help in providing the approval for the conduction of the study at the National Center for Diabetes, Endocrinology and Genetics.

Contributors The authors who contributed to the work described in this paper are as follows: ICKW and LW contributed to the study design. AYN and DA-HH conducted the study and collected data. AYN, KKCM, WCYL and LW contributed to the data analysis. AYN, KKCM, WCYL, ICKW, LW, CW, MYB and DA-HH were involved in interpretation of data. AYN wrote the first draft of the article. All authors reviewed the manuscript for important intellectual content and provided final approval of the version to be published. All authors agreed to be accountable for all aspects of the work in ensuring that questions related to the accuracy or integrity of any part of the work are appropriately investigated and resolved.

Funding AYN was supported by a scholarship from ISRA University, Jordan for his PhD project.

Competing interests None declared.

Patient consent Not required.

Ethics approval This study was approved by the Research Ethics Committee of the National Center for Diabetes, Endocrinology and Genetics in Jordan and UCL Research Ethics Committee, the UK.

Provenance and peer review Not commissioned; externally peer reviewed. Data sharing statement No additional data are available.

Open access This is an open access article distributed in accordance with the Creative Commons Attribution Non Commercial (CC BY-NC 4.0) license, which permits others to distribute, remix, adapt, build upon this work non-commercially, and license their derivative works on different terms, provided the original work is properly cited, appropriate credit is given, any changes made indicated, and the use is non-commercial. See: http://creativecommons.org/licenses/by-nc/4.0/.

\section{REFERENCES}

1. Hanssen KF. Blood glucose control and microvascular and macrovascular complications in diabetes. Diabetes 1997;46 Suppl 2:S101-S103.

2. Riedel AA, Heien $\mathrm{H}$, Wogen J, et al. Loss of glycemic control in patients with type 2 diabetes mellitus who were receiving initial metformin, sulfonylurea, or thiazolidinedione monotherapy. Pharmacotherapy 2007;27:1102-10.

3. Turner R, Cull C, Frighi V, et al. Glycemic control with diet, sulfonylurea, metformin, or insulin in patients with type 2 diabetes mellitus. J of the American Med Association 1999;281:2005-12.

4. Lavernia F, Adkins SE, Shubrook JH. Use of oral combination therapy for type 2 diabetes in primary care: Meeting individualized patient goals. Postgrad Med 2015;127:808-17.

5. Zaccardi F, Davies MJ, Dhalwani NN, et al. Trends in hospital admissions for hypoglycaemia in England: a retrospective, observational study. Lancet Diabetes Endocrinol 2016;4:677-85.

6. Lipska KJ, Ross JS, Wang Y, et al. National trends in US hospital admissions for hyperglycemia and hypoglycemia among Medicare beneficiaries, 1999 to 2011. JAMA Intern Med 2014;174:1116-24.

7. Naser AY, Wang Q, Wong LYL, et al. Hospital Admissions due to Dysglycaemia and Prescriptions of Antidiabetic Medications in England and Wales: An Ecological Study. Diabetes Ther 2018;9.

8. NCDEG Mission. The National Center for Diabetes Endocrinology and Genetics. 2017 http://www.ncd.org.jo/index.php?option=com content\&view=article\&id=48\&ltemid=86 (accessed 25 Jan 2018).

9. EASD - NCDEG. The National Center for Diabetes Endocrinology and Genetics Research. 2017 http://www.ncd.org.jo/index.php?option= com_content\&view=article\&id=85\&ltemid=74 (accessed 25 Jan 2018). 
10. Maclure M. The case-crossover design: a method for studying transient effects on the risk of acute events. Am J Epidemiol 1991;133:144-53.

11. Lao KS, Chui CS, Man KK, et al. Medication safety research by observational study design. Int J Clin Pharm 2016;38:676-84.

12. Delaney JA, Suissa S. The case-crossover study design in pharmacoepidemiology. Stat Methods Med Res 2009;18:53-65.

13. Wong AY, Root A, Douglas IJ, et al. Cardiovascular outcomes associated with use of clarithromycin: population based study. BMJ 2016;352:h6926.

14. Fournier JP, Azoulay L, Yin H, et al. Tramadol use and the risk of hospitalization for hypoglycemia in patients with noncancer pain. JAMA Intern Med 2015;175:186-93.

15. Leach MJ, Pratt NL, Roughead EE. Psychoactive medicine use and the risk of hip fracture in older people: a case-crossover study. Pharmacoepidemiol Drug Saf 2015;24:576-82.

16. Maclure M, Mittleman MA. Should we use a case-crossover design? Annu Rev Public Health 2000;21:193-221.

17. Workgroup on Hypoglycemia, American Diabetes Association. Defining and reporting hypoglycemia in diabetes: a report from the American Diabetes Association Workgroup on Hypoglycemia. Diabetes Care 2005;28:1245-9.

18. Brunelli SM, Gagne JJ, Huybrechts KF, et al. Estimation using all available covariate information versus a fixed look-back window for dichotomous covariates. Pharmacoepidemiol Drug Saf 2013;22:542-50.
19. Hennessy S, Bilker WB, Berlin JA, et al. Factors influencing the optimal control-to-case ratio in matched case-control studies. Am J Epidemiol 1999;149:195-7.

20. Hippisley-Cox J, Coupland C. Diabetes treatments and risk of amputation, blindness, severe kidney failure, hyperglycaemia, and hypoglycaemia: open cohort study in primary care. BMJ 2016;352:i1450.

21. World Health Organization. BMI classification. 2018 http://apps. who.int/bmi/index.jsp?introPage=intro_3.html (accessed 25 Jan 2018)

22. Ahrén B. Avoiding hypoglycemia: a key to success for glucoselowering therapy in type 2 diabetes. Vasc Health Risk Manag 2013:9:155-63.

23. Kim HM, Seong JM, Kim J. Risk of hospitalization for hypoglycemia among older Korean people with diabetes mellitus: Interactions between treatment modalities and comorbidities. Medicine 2016;95:e5016.

24. Murad MH, Coto-Yglesias F, Wang AT, et al. Clinical review: Druginduced hypoglycemia: a systematic review. J Clin Endocrinol Metab 2009;94:741-5.

25. Diabetes In Control. Drugs that can affect blood glucose levels. 2017 http://www.diabetesincontrol.com/drugs-that-can-affect-bloodglucose-levels/\#causehypo (accessed 25 Jan 2018).

26. Ekman B. The impact of health insurance on outpatient utilization and expenditure: evidence from one middle-income country using national household survey data. Health Res Policy Syst 2007;5:6. 